\title{
The Multiple Impact of Education Gaps in Romania
}

\author{
Diana-Maria Cismaru and Nicoleta Corbu
}

\section{Literature Review}

The systemic perspective in education presents two important applications of functional analysis: the ecological approach, from which was derived the concept of sustainable development in education (Dale and Newman 2005), and the perspective focused on the concept of quality, a concept that emphasizes the need to increase the effectiveness and performance of educational systems (Alexander 2000). Reflecting on the differences between the European and United States systems of education, Sallis (2014, p.10) reviewed the principles and indicators in Total Quality Management (a perspective from which emerged a series of instruments and indicators that influenced the educational institutions' management) and observed that in the US, educational institutions, most of them private, have a market-view orientation and are centred more on efficacy and profit. By contrast, in Europe the educational institutions are focused on quality of knowledge and services, relying more on public confidence.

Reviewing over 200 studies on education published in 20 years, Glewwe et al. (2011, pp. 22-25) synthesized the impact factors on three important elements: the infrastructure and educational resources, the characteristics of teachers, and the organization of school; A more recent study (Ganimian and Murnane 2016) identified four "lessons" learnt from more than 50 countries to increase students' achievements, among which was reducing the costs of going to school.

This chapter has been prepared with financial support granted in the project "State of the Nation. Designing an innovative instrument for evidence-based policy-making" (SIPOCA 11, MySMIS 118305), which is co-financed by the European Social Fund through the Operational Programme Administrative Capacity 2014-2020.

D.-M. Cismaru $(\bowtie) \cdot$ N. Corbu $(\bowtie)$

National University of Political Studies and Public Administration, Bucharest, Romania e-mail: diana.cismaru@comunicare.ro; nicoleta.corbu@comunicare.ro 
According to the human capital perspective, education is an investment of current resources (time, effort, money) in exchange for future returns (Harmon et al. 2001, p. 3). Several authors explored the returns of education, associating it with material individual benefits such as a better position on the labour market or increased earnings (Card 1999; Rouse 2007), the improvement of occupational status, and an increased social mobility (Buchmann and Hannum 2001, p. 89). On the other hand, synthesizing studies from over several decades, Wolfe and Haveman (2002, pp. 104-105) presented several non-material outcomes of education: better relationships, better health, longer life, more educated children.

The emphasis on education outcomes raises the issue of gaps, whether they are created between social categories, territorial units (countries, regions) or societies. The issue of education gaps has been considered a strategic problem to be addressed in future policies (Glewwe et al. 2011). Several types of education gaps have been documented in studies: for example, social class and race as sources of gaps since the beginning of school have been demonstrated in the case of American children (Hemphill and Vanneman 2011; Garcia and Weiss 2015); gender inequality was also investigated, considering the influence on economic growth in the long term (Klasen 2002; Breen et al. 2009). Disadvantaged groups and poverty were identified as bases for educational inequality (Duncan et al. 2011) and as priority targets in evidence-based policies for increasing education equity (Ladd 2012). Not only were the factors that influence gaps investigated in studies but also the features of the gaps, such as differences in participation and achievement (Reardon et al. 2014).

While questioning the effectiveness of education systems, several studies explored the variety of factors that shape educational inequality on multiple levels: Buchmann and Hannum (2001) identified four categories of factors: (a) macrostructural forces shaping educational stratification (education policies, funding); (b) the impact of family background on educational attainment and achievement; (c) school factors related to educational outcomes; (d) the impact of education on social mobility in developing regions. The authors also discuss the lack of research on the influence of communities in education outcomes, and the need to initiate cross-country studies.

The overlapping of gaps between developed and less developed societies was one of the issues debated by researchers in education. Glewwe and Muralidharan (2015, pp. 10-11) observed that in the less developed countries, the conversion of the participation rate in outcomes of education (knowledge and skills) is weak. The main challenges identified for increasing quality of results in education in developing countries were improving access to pre- and post-primary education, using technology to improve pedagogy, management and accountability, and developing appropriate policies to support private schools (Kremer et al. 2013, p. 299). Evaluating progress in education by reviewing 115 impact evaluation studies in 33 countries, Murnane and Ganimian (2014, pp. 43-44) discovered several effects of policies: reducing costs of school improves participation but not achievement while providing information about school quality and return of schooling improves achievement, and also daily experience of students' and teachers' incentives improve pupils' achievements. 


\section{Methodology}

In the context exposed in the previous section, we aim at identifying the main aspects of educational inequalities in the case of Romania and their impact on future development. To this purpose, we conducted a secondary data analysis using official data from UNESCO and Eurostat databases. The basis for analysis consists of three key indicators: gross enrolment ratio, the average rate of early leavers from education and training, and tertiary educational attainment. These indicators were selected because they provide integrative insights into the results of educational processes, are subject to educational policies and, at the same time, targets of Europe 2020 strategies. Thus, the gross enrolment ratio shows the proportion of pupils enrolled in a specific level of education, regardless of age, expressed as a percentage of the population in the official age group corresponding to this level of education. The early school leavers are defined as the persons aged 18-24 for whom the highest level of education attained is ISCED 0,1 or 2 . Finally, the tertiary educational attainment indicator is defined as the share of the population aged 30-34 who have successfully completed a tertiary education programme (ISCED 5-6). Additionally, we use a support indicator, the structure of population by level of educational attainment. The research questions guiding the analysis are:

RQ1. What are the particularities of educational inequalities among the Romanian regions of development in terms of level of education attained?

RQ2. In regard to the level of educational attainment, what are the tendencies of evolution in Romania in comparison with the tendencies of evolution in other European countries?

RQ3. What are the changes in the Romanian structure of population in terms of level of educational attainment in the last ten years?

The general objective of this contribution is to identify disparities within regions, and within the Eastern European region (in the context of the European Union as a benchmark), aiming at distinguishing patterns of development in education for Romania, in comparison with other patterns of development, and the potential consequences of this evolution.

\section{Findings}

In Romania, the development of schools, which are mainly public, depends mainly on the level of public financing of education, which was the lowest in Europe (around 2,7\% of GDP in the last years) (Eurostat, 2014, last available data, variable educ_uoe_fine06). The low level of financing is reflected in the decrease of enrolment at all levels and the teachers' lack of motivation, transforming the human resources in education into a persistent problem. In 2015, the average net monthly earning in education was approximately 420 euros, less than the earnings in other 


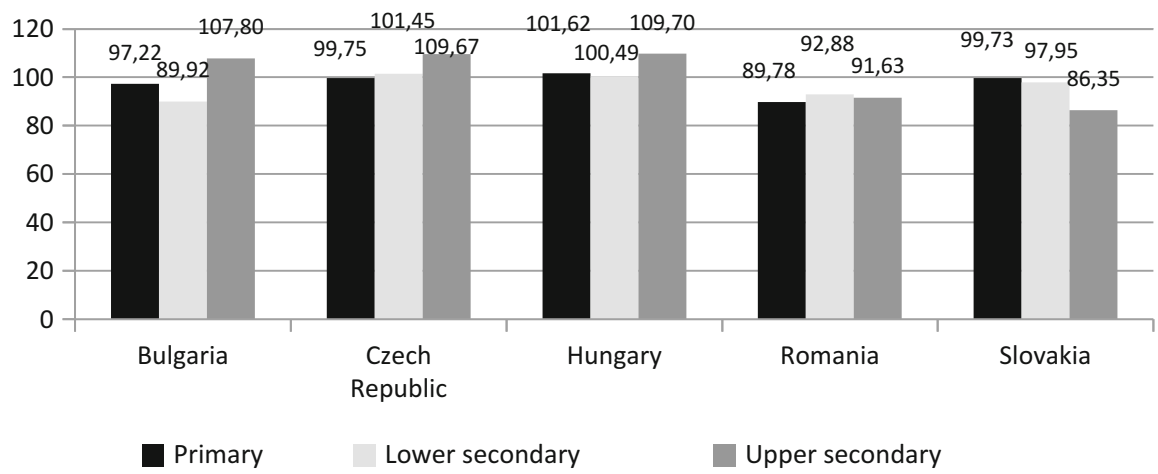

Fig. 1 Gross enrolment ratio in primary, lower secondary and upper secondary levels in $2015(\%)$. (The latest year with available data is 2015 ; there is no data available for Poland and Slovenia (newest data for these countries dates from 2013). Source: UNESCO, http://data.uis.unesco.org/ index.aspx?queryid $=142 \#$

fields such as insurance, public administration, consultancy, and communications (Romanian National Institute of Statistics, variable FOM106E).

The gross enrolment ratio is important because it reveals the share of participation in the different cycles of education. In Romania, the positive evolution of enrolment rates between 2002 and 2008 was influenced by public policies and a moderate economic improvement. But, after 2008, enrolment decreased in primary, lower secondary and upper secondary levels (UNESCO, variable "Gross enrollment rates, by level of education"). For example, for the upper secondary level, the decrease was of approximately 4-5\% after 2012, reaching 91.6\% in 2015. When comparing Romania with other former communist countries, Romania had, in 2015, the lowest level of participation in primary school (89.78\%) (Fig. 1), while the other four countries selected had levels of participation between 97.22\% (Bulgaria) and $101.62 \%$ (Hungary). Moreover, the gross enrolment ratio in lower secondary level in Romania was 92.88\%, lower than the Czech Republic, Slovakia, and Hungary.

The evolution of tertiary educational attainment (Fig. 2) is included in the same pattern. Even if Romania has made significant progress in ten years, increasing from 8.9 to $25.6 \%$, it still remains the lowest percentage among the former communist countries, and rather far from the average share in the European Union $(39.1 \%$ in 2016). In Poland, for example, the share of population aged 30-34 with higher education was $44.6 \%$ in 2016.

The third indicator selected for this study, the rate of early school leavers, reveals the other side of the gap between Romania and the other European countries. Thus, Romania has the highest level of this indicator in the European Union $(18.6 \%$ in 2016), while the mean in European Union decreased to $10.7 \%$. The former communist countries have lower levels or approximately the same level with the EU mean value (Fig. 3).

The rate of early school leavers by residence explains the source of the country gap of Romania. Thus, in 2016, if the rate of early school leavers in Romanian cities 


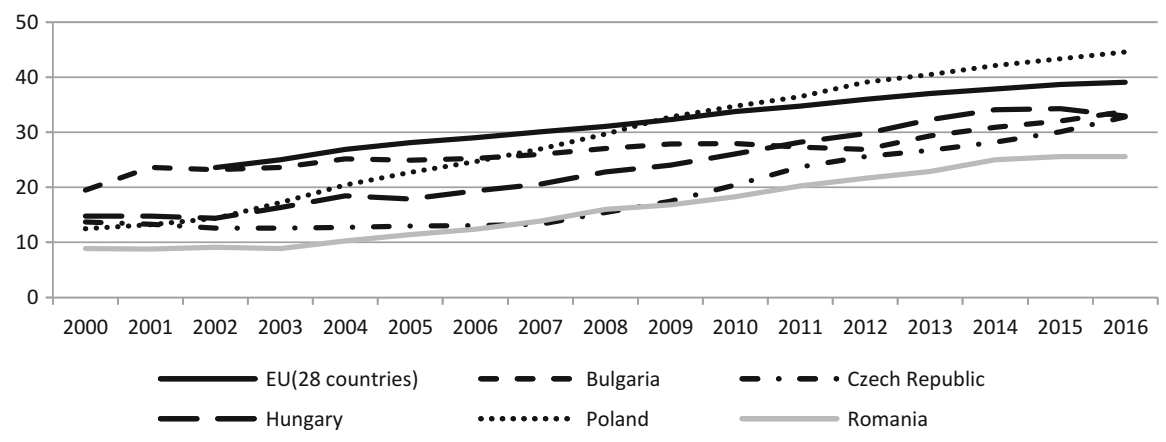

Fig. 2 Tertiary educational attainment (30-34 years) (\%). Source: Eurostat, variable edat_lfse_12

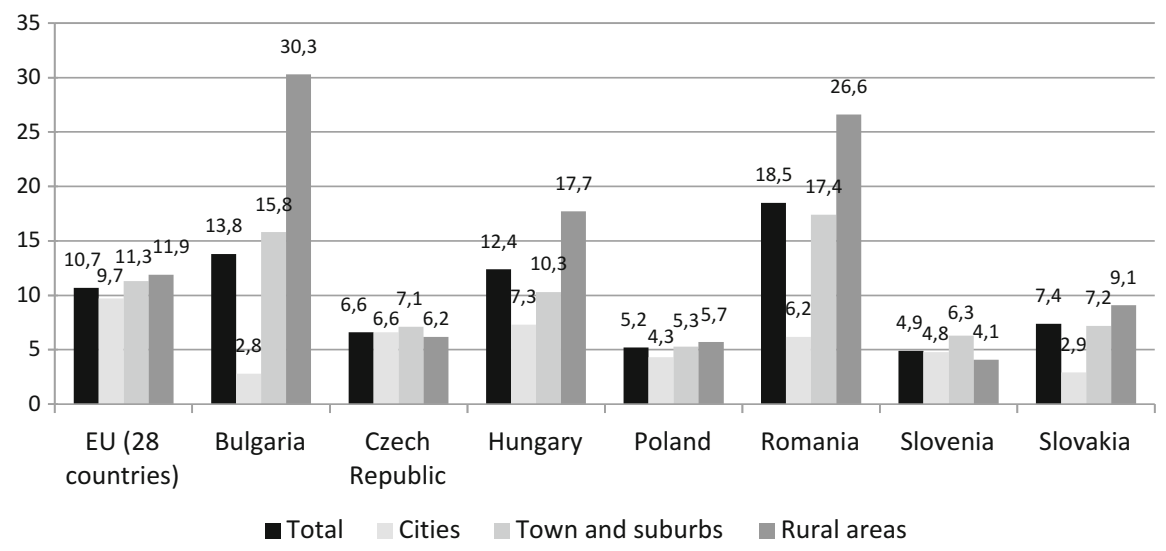

Fig. 3 The rate of early school leavers (18-24 years), by residence, in 2016. Source: Eurostat, variable edat_lfse_30

is comparable with the same rate in the developed European countries and with the EU mean, the rates in Romania's towns and suburbs (17.4\%) and, respectively, in rural areas $(26.6 \%)$ are much higher in comparison with the same rate in cities (only $6.2 \%$ ). Romania and Bulgaria are the only two countries with a large difference created by residence (Fig. 3).

The evolution of the two indicators considered above should be interpreted in connection with the changes in the structure of population by level of instruction. For the entire adult population (aged 25-64 years) the changes are slower, while for the younger age group, changes might be more easily obtained as the effect of policies. Thus, for the population aged 30-34 in different European countries (Table 1), several patterns of evolution can be identified. In some European countries, with a high share of population with a low level of instruction (ISCED 0-2) and a low share of population with tertiary education (ISCED 5-8), a positive change registered in 
Table 1 Population aged 30-34 in different European countries by level of educational attainment (2000, 2007, 2016-comparison)

\begin{tabular}{|c|c|c|c|c|c|}
\hline Country & Level of education & Level of education & 2000 & 2007 & 2016 \\
\hline \multirow[t]{3}{*}{ EU ( 28 countries $)$} & Low & ISCED 0-2 & & 21.7 & 17.2 \\
\hline & Medium & ISCED 3-4 & & 48.3 & 43.7 \\
\hline & High & ISCED 5-8 & & 30.1 & 39.1 \\
\hline \multirow[t]{3}{*}{ Belgium } & Low & ISCED 0-2 & 27.4 & 18.9 & 17.5 \\
\hline & Medium & ISCED 3-4 & 37.5 & 39.6 & 37.0 \\
\hline & High & ISCED 5-8 & 35.2 & 41.5 & 45.6 \\
\hline \multirow[t]{3}{*}{ Bulgaria } & Low & ISCED 0-2 & 23.7 & 17.9 & 17.9 \\
\hline & Medium & ISCED 3-4 & 56.8 & 56.1 & 48.3 \\
\hline & High & ISCED 5-8 & 19.5 & 26.0 & 33.8 \\
\hline \multirow[t]{3}{*}{ Greece } & Low & ISCED 0-2 & 30.9 & 25.8 & 17.1 \\
\hline & Medium & ISCED 3-4 & 43.7 & 47.9 & 40.2 \\
\hline & High & ISCED 5-8 & 25.4 & 26.3 & 42.7 \\
\hline \multirow[t]{3}{*}{ France } & Low & ISCED 0-2 & 26.0 & 18.1 & 14.2 \\
\hline & Medium & ISCED 3-4 & 46.5 & 40.5 & 42.2 \\
\hline & High & ISCED 5-8 & 27.4 & 41.4 & 43.6 \\
\hline \multirow[t]{3}{*}{ Italy } & Low & ISCED 0-2 & 44.2 & 34.8 & 28.8 \\
\hline & Medium & ISCED 3-4 & 44.2 & 46.7 & 45.1 \\
\hline & High & ISCED 5-8 & 11.6 & 18.6 & 26.2 \\
\hline \multirow[t]{3}{*}{ Hungary } & Low & ISCED 0-2 & 18.6 & 15.4 & 14.1 \\
\hline & Medium & ISCED 3-4 & 66.7 & 64.0 & 53.0 \\
\hline & High & ISCED 5-8 & 14.8 & 20.6 & 33.0 \\
\hline \multirow[t]{3}{*}{ Poland } & Low & ISCED 0-2 & 11.3 & 8.5 & 5.3 \\
\hline & Medium & ISCED 3-4 & 76.2 & 64.4 & 50.1 \\
\hline & High & ISCED 5-8 & 12.5 & 27.0 & 44.6 \\
\hline \multirow[t]{3}{*}{ Portugal } & Low & ISCED 0-2 & 74.3 & 60.2 & 33.9 \\
\hline & Medium & ISCED 3-4 & 14.4 & 20.3 & 31.5 \\
\hline & High & ISCED 5-8 & 11.3 & 19.5 & 34.6 \\
\hline \multirow[t]{3}{*}{ Romania } & Low & ISCED 0-2 & 12.1 & 20.0 & 23.4 \\
\hline & Medium & ISCED 3-4 & 78.9 & 66.0 & 51.0 \\
\hline & High & ISCED 5-8 & 8.9 & 13.9 & 25.6 \\
\hline \multirow[t]{3}{*}{ Spain } & Low & ISCED 0-2 & 49.2 & 35.0 & 35.4 \\
\hline & Medium & ISCED 3-4 & 21.7 & 24.2 & 24.5 \\
\hline & High & ISCED 5-8 & 29.2 & 40.9 & 40.1 \\
\hline
\end{tabular}

Source: Eurostat, variable edat_lfse_12

only ten years (this is the case of Portugal, Italy, and Greece). In other countries with the same problem, the levels of indicators stagnated during the last 10 years (the case of Spain). In a third group of countries, such as Belgium and France, an analysis of the indicators shows a substantial decrease of population with low levels of instruction (ISCED 0-2) until 2007, and an improvement to a certain extent after 2007. In other countries, such as Poland, the share of people with low levels of instruction 
was rather small, and then decreased even more in the last ten years. Finally, in Romania, the share of population aged 30-34 years with a high level of instruction increased after 2007 from 14 to $25.6 \%$ (almost reaching the national objective in Europe 2020 Strategy), but increased more in the population with medium levels of instruction (ISCED 3-4), whose share decreased in the same period from 66 to $51 \%$ (Bulgaria and Hungary are in the same situation). At the same time, the share of population aged 30-34 years having a low level of education (ISCED 0-2) slightly increased after 2007 (from 20 to $23 \%$ ). Romania is the only case in which the problem became very prominent in 2007 (the share of population aged 30-34 with a low level of instruction doubled from 2000 to 2007) and also the only one for which the share of population with a low level of instruction increased instead of decreased (Table 1).

The same analysis performed on the whole adult population (aged 25-64) reveals slower changes in the three strata of the population. In the group of former communist countries, Romania has the highest share of individuals with a low level of instruction $(23.3 \%$ in 2016) and the lowest share of persons with a high level of instruction (17.4\% in 2016). Also, we observe again that the increase in the share of the population aged 25-64 years with a high level of instruction was produced to the detriment of those with a medium level of instruction (which decreased from $63 \%$ in 2007 to $59.4 \%$ in 2016), while those with a low level of instruction only slightly decreased, from $25 \%$ in 2007 to $23.3 \%$ in 2016 (Fig. 4).

Continuing the analysis of the educational attainment for the Romanian regions of development, we observe strong differences. Thus, in Bucharest-Ilfov, the most developed region of Romania, the tertiary educational attainment was $47.8 \%$ in 2016 (higher than the average level of the EU for this indicator-39.1\% in 2016), while the rate of early school leavers was only $10 \%$ in the same year (almost equal with the average level of EU). By contrast, in the other regions, the highest level of tertiary

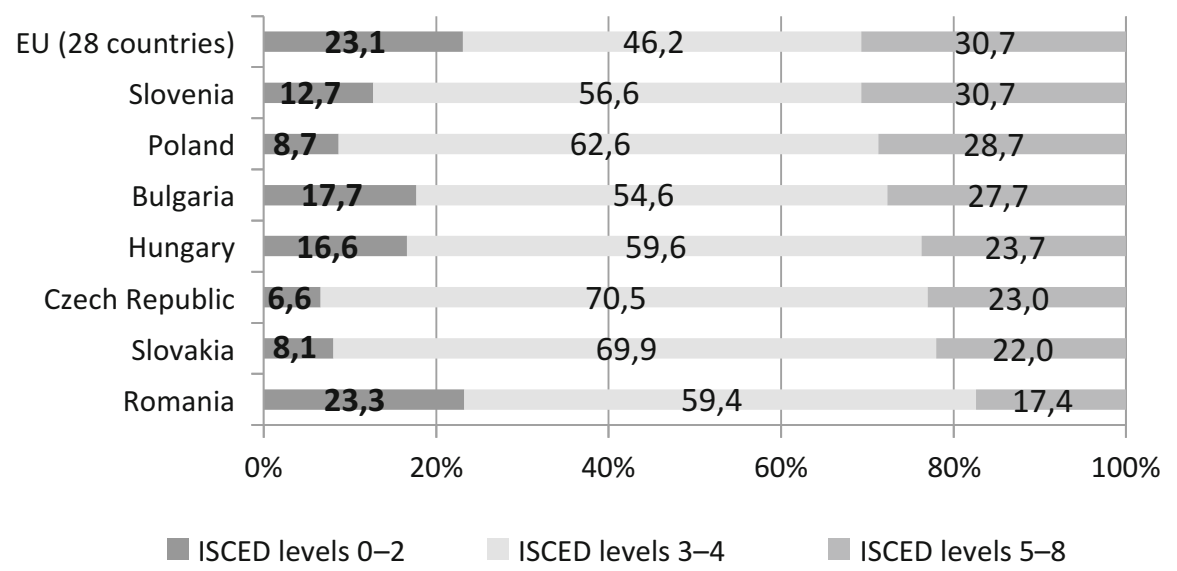

Fig. 4 Population aged 25-64 years by level of educational attainment, 2016 (\%). Source: Eurostat, variable edat_lfse_04 


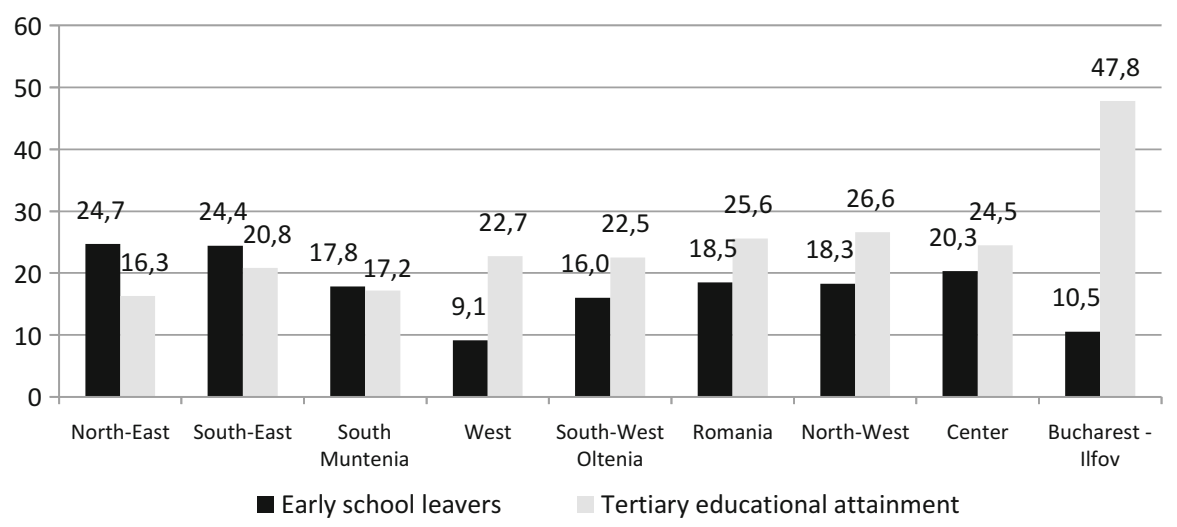

Fig. 5 The rate of early school leavers (18-24 years) and the tertiary educational attainment (30-34 years) in 2016 (\%). Source: Eurostat, variables edat_lfse_16 and edat_lfse_12

educational attainment was $26.6 \%$ (North-West) and, in all the other regions except the West, the rate of early school leavers was higher than $16 \%$. The poorest region, North-East, presents the opposite when compared with Bucharest-Ilfov: almost one quarter of those aged 18-24 did not complete the upper secondary level, and only $16.3 \%$ of those aged 30-34 years completed the higher education level (Fig. 5).

Analyzing the effect of changes in educational attainment in the entire adult population (aged 25-64 years), one can better observe the gaps between the Romanian regions of development (Table 2). Thus, the advance of Bucharest-Ilfov originated before 2000: the percentage of adult population with a high level of instruction was $20.1 \%$ in 2000 , at least double any other region, while the rate of early school leavers was approximately half of the rate of the other regions of development. Furthermore, while in 20 years one could observe a slow improvement in the level of educational attainment in almost all the regions, in the poorest region (North-East) there was merely a stagnation and even a slow increase in the percentage of persons with a low level of instruction (from $28.1 \%$ in 2007 to $30.7 \%$ in 2016). Also, in most of the regions, the improvement was more prominent before 2007 than after.

\section{Interpretation}

Generally speaking, we identified two types of gaps in education: external gaps (a moderate gap between Romania and the other countries in the post-communist group of countries, and a larger gap between Romania and other European countries) and internal gaps, which build a heterogeneous picture of Romania and are at the same time sources for the country gaps identified at first glance. The gaps manifest as polarizations not only between social categories but also between areas of residence and regions of development. 
Table 2 Population aged 25-64 in Romanian regions of development by level of educational attainment (2000, 2007, 2016-comparison)

\begin{tabular}{|c|c|c|c|c|c|}
\hline $\begin{array}{l}\text { Regions of development } \\
\text { (NUTS2) }\end{array}$ & Level of education & Level of education & 2000 & 2007 & 2016 \\
\hline \multirow[t]{3}{*}{ EU ( 28 countries) } & Low & ISCED 0-2 & & 29.3 & 23.1 \\
\hline & Medium & ISCED 3-4 & & 47.2 & 46.2 \\
\hline & High & ISCED 5-8 & & 23.5 & 30.7 \\
\hline \multirow[t]{3}{*}{ Romania } & Low & ISCED 0-2 & 30.7 & 25.0 & 23.3 \\
\hline & Medium & ISCED 3-4 & 60.0 & 63.0 & 59.4 \\
\hline & High & ISCED 5-8 & 9.3 & 12.0 & 17.4 \\
\hline \multirow{3}{*}{ North-West } & Low & ISCED 0-2 & 33.0 & 25.8 & 24.5 \\
\hline & Medium & ISCED 3-4 & 58.2 & 63.1 & 58.1 \\
\hline & High & ISCED 5-8 & 8.8 & 11.0 & 17.4 \\
\hline \multirow[t]{3}{*}{ Center } & Low & ISCED 0-2 & 27.3 & 22.8 & 23.2 \\
\hline & Medium & ISCED 3-4 & 64.4 & 66.0 & 59.3 \\
\hline & High & ISCED 5-8 & 8.3 & 11.1 & 17.5 \\
\hline \multirow[t]{3}{*}{ North-East } & Low & ISCED 0-2 & 34.5 & 28.1 & 30.7 \\
\hline & Medium & ISCED 3-4 & 58.7 & 61.6 & 57.7 \\
\hline & High & ISCED 5-8 & 6.8 & 10.3 & 11.5 \\
\hline \multirow[t]{3}{*}{ South-East } & Low & ISCED 0-2 & 33.8 & 30.0 & 28.2 \\
\hline & Medium & ISCED 3-4 & 57.4 & 61.2 & 58.9 \\
\hline & High & ISCED 5-8 & 8.8 & 8.8 & 12.9 \\
\hline \multirow[t]{3}{*}{ South-Muntenia } & Low & ISCED 0-2 & 33.6 & 27.8 & 23.8 \\
\hline & Medium & ISCED 3-4 & 59.9 & 63.6 & 63.0 \\
\hline & High & ISCED 5-8 & 6.5 & 8.6 & 13.3 \\
\hline \multirow[t]{3}{*}{ Bucharest-Ilfov } & Low & ISCED 0-2 & 16.7 & 13.2 & 13.0 \\
\hline & Medium & ISCED 3-4 & 63.2 & 60.4 & 51.9 \\
\hline & High & ISCED 5-8 & 20.1 & 26.3 & 35.1 \\
\hline \multirow[t]{3}{*}{ South-West Oltenia } & Low & ISCED 0-2 & 32.4 & 24.9 & 20.8 \\
\hline & Medium & ISCED 3-4 & 59.8 & 64.0 & 62.3 \\
\hline & High & ISCED 5-8 & 7.8 & 11.1 & 16.8 \\
\hline \multirow[t]{3}{*}{ West } & Low & ISCED 0-2 & 30.2 & 24.0 & 18.8 \\
\hline & Medium & ISCED 3-4 & 59.3 & 64.6 & 65.7 \\
\hline & High & ISCED 5-8 & 10.6 & 11.4 & 15.5 \\
\hline
\end{tabular}

Source: Eurostat, variable edat_lfse_04

The polarization can be identified starting from the participation rates. A high share of participation is a precondition for relevant academic achievements and for the quality of knowledge and skills gained by graduates. A share of more than $10 \%$ of pupils of the appropriate age not enrolled in primary school (which is the first compulsory level) reveals great social difficulties and a low level of motivation in the pupils' families. This share of children not enrolled in primary school not only creates a premise for lower shares of participation in the next levels but also determines the existence, in the future, of a large category of individuals with a total lack of basic skills for social life and qualifications. Meanwhile, analyzing 
participation in other levels of education, the cumulated levels of enrolment are the lowest in the case of Romania, showing that the premises for educational achievement are affected.

Depicting the internal disparities in Romania, a first important gap was observed when introducing residence as a structuring criterion: the rate of early leavers is 4.5 times higher in rural areas in comparison with cities, and 3 times higher in towns and suburbs in comparison with cities. Thus, a particular feature of Romania (and Bulgaria) is a profound educational inequality between different areas of residence. Secondly, an analysis of regions of development in Romania in terms of early school leaving, tertiary educational attainment and structure of population by level of instruction shows important inequalities: early school leaving is 2.5 times more intense in the poor regions (North-East) in comparison with Bucharest-Ilfov (compatible with the EU average, 11\%), while the tertiary education attainment in the total population of 30-34 years from Bucharest-Ilfov (48.4\%) is 3 times more than in the North-East (15.8\%). The premises for avoiding poverty and exclusion, for better health, building a successful career, and increasing earnings and family welfare are very different among the Romanian regions of development.

Moreover, while some of the Western European countries made important steps before 2007 to improve the share of population aged 30-34 with a high level of educational attainment and continued after 2007 (the cases of France, Belgium and Poland), other countries registered an accelerated improvement of this aspect after 2007 (Portugal, Italy and Greece). In this regard, Romania and Hungary had a similar pattern of evolution, which consisted of improving the share of population with tertiary educational attainment, but on behalf of the population with medium level of instruction (whose proportion decreased), while the share of population with a low level of educational attainment has remained almost at the same level in the last ten years. This pattern is worrisome because, in an organic development, the level of educational attainment should increase for all three categories of population. A relatively high share of the population with a low level of instruction means a high risk of poverty, social exclusion and a great range of other problems in the future for a large number of young people.

Finally, in terms of adult and young populations by level of instruction, even if in the last 20 years a gradual improvement is visible in Romania, the gap between the regions of development is more accentuated in the last period (the poorest regions, the North-East and, in some respects, the South-East present merely a stagnation).

\section{Discussion}

Education is a significant source of improvement of the human capital as a basis for welfare in the economy and society. There is a circular relationship between the development of human capital and the wellbeing of society (Glewwe and Muralidharan 2015, p. 3). At a social level, education has a positive influence on economic growth and improves the wellbeing of societies by forming informed and 
responsible consumers, increasing citizenship, democratic participation and, finally, the health and lifespan of the citizens (Wolfe and Haveman 2002; Lochner 2011). On the other hand, the labour market now needs to adapt to a new digital and globalized society and thus graduates should be more competent and specialized.

Several studies from the socio-economical field calculated the impact of education completion on individual earnings. Comparing census data for youth from the US, Canada and the UK, Oreopoulos (2003, p. 17) discovered that one year of compulsory schooling raises subsequent annual earnings by $10-14 \%$; also, a one-year increase in schooling decreases by $6 \%$ the probability of being reported as poor and by $3.2 \%$ the probability of reporting poor health in the US (Oreopoulos 2003, p. 18). Meanwhile, Rouse (2007) explored the impact of educational attainment level on employability status and income. Only 50\% of the individuals without high school completion were employed compared to $69 \%$ of individuals with a high school degree, and $75 \%$ of the individuals with at least a high school diploma. Further, high school dropouts contributed only $40 \%$ to tax revenues compared to employees with a high school diploma (Rouse 2007, p. 120), showing an important difference in income and demonstrating the importance of education.

These studies emphasize the positive impact of education on the life of individuals and reveal that increasing the quality of human capital by education contributes essentially to the shape of a post-industrialized, globalized society. Subsequently, the findings analyzed in this study raise pessimistic reflections about the future impact of the educational gaps in Romania. Due to the large differences among populations from the regions of development in terms of educational attainment, the human capital characteristics will be very different. Thus, the evolutions in the future will be divergent and no model of homogeneous development will be applicable. In vicious circles, the undesirable characteristics of the poorer development regions will intensify, making impossible the attempts to improve the situation (for example, attempts to launch local firms or subsidiaries for larger companies). Meanwhile, because a quarter of young people in rural areas (or one in six individuals in the whole adult population) have not completed the upper secondary education level, economic development will be affected in the future by the lack of qualified workforce. Also, this large proportion of individuals with a low level of instruction and employability is a source of social problems in the medium and long term, contributing to the intensification of poverty and crime. Moreover, the fact that one in ten children was not enrolled in the primary school level in 2015 (the lowest rate in the last twenty years) shows that the issue of this category of population, with all its consequences, will probably magnify in the future.

\section{Conclusions}

With the aim of identifying the differences in terms of educational disparities in Romania, the present research focused on the level of educational attainment, expressed by two key indicators (the rate of early school leaving and tertiary 
educational attainment - and, as support indicators, the gross enrolment ratio and the structure of population by the level of instruction). Relying on the last data released by Eurostat and UNESCO database, the study identified a series of educational gaps in Romania. First, the external gap placed Romania in the same group with Bulgaria and Hungary, on the one hand, and in the same group of countries with an important share of people with a low level of instruction (together with Spain, Portugal and Italy) on the other hand. In contrast to all of these countries, in Romania the share of population with a low level of instruction increased between 2000 and 2007 and did not decrease significantly after 2007.

Furthermore, the identification of internal educational disparities explains in part the external gaps of the country. Thus, the urban areas (cities, towns and suburbs) and the rural regions show large differences in terms of educational attainment and structure of population by level of instruction. These large differences create not only a very heterogeneous picture in the development of the Romanian urban and rural areas but also a mutual detachment when these gaps intensify in the future, producing "different worlds" whose tendency will be to evolve differently, in two opposite directions (progress versus underdevelopment). The impact of the educational gaps identified above will be very costly in the years to come, mainly when the population with a low level of instruction and weak qualifications and skills will be exposed to long-term unemployment, poverty, poor health, social exclusion, and higher crime rates. Therefore, new educational policies in Romania, focused on increasing the enrolment and the level of education attainment by stimulating the returns of education, should become a priority in the next decade.

\section{References}

Alexander, F. K. (2000). The changing face of accountability: Monitoring and assessing institutional performance in higher education. The Journal of Higher Education, 71(4), 411-431.

Buchmann, C., \& Hannum, E. (2001). Education and stratification in developing countries: A review of theories and research. Annual Review of Sociology, 27(1), 77-102.

Card, D. (1999). The causal effect of education on earnings. Handbook of Labor Economics, 3, 1801-1863.

Dale, A., \& Newman, L. (2005). Sustainable development, education and literacy. International Journal of Sustainability in Higher Education, 6(4), 351-362.

Duncan, G. J., Morris, P. A., \& Rodrigues, C. (2011). Does money really matter? Estimating impacts of family income on young children's achievement with data from random-assignment experiments. Developmental Psychology, 47(5), 1263-1279.

Ganimian, A. J., \& Murnane, R. J. (2016). Improving education in developing countries: Lessons from rigorous impact evaluations. Review of Educational Research, 86(3), 719-755.

Garcia, E., \& Weiss, E. (2015). Early education gaps by social class and race start US children out on unequal footing: A summary of the major findings in inequalities at the starting gate. Washington, DC: Economic Policy Institute.

Glewwe, P. W., \& Muralidharan, K. (2015). Improving school education outcomes in developing countries: Evidence, knowledge gaps, and policy implications. University of Oxford, Research on Improving Systems of Education (RISE). 
Glewwe, P. W., Hanushek, E. A., Humpage, S. D., \& Ravina, R. (2011). School resources and educational outcomes in developing countries: A review of the literature from 1990 to 2010 (Working paper 17554). Accessed January 19, 2018, from http://www.nber.org/papers/w17554

Harmon, C., Walker, I., \& Westergærd-Nielsen, N. C. (Eds.). (2001). Education and earnings in Europe: A cross country analysis of the returns to education. Cheltenham: Edward Elgar.

Hemphill, F. C., \& Vanneman, A. (2011). Achievement gaps: How hispanic and white students in public schools perform in mathematics and reading on the National Assessment of Educational Progress. Statistical Analysis Report. NCES 2011-459. National Center for Education Statistics.

Klasen, S. (2002). Low schooling for girls, slower growth for all? Cross-country evidence on the effect of gender inequality in education on economic development. The World Bank Economic Review, 16(3), 345-373.

Kremer, M., Brannen, C., \& Glennerster, R. (2013). The challenge of education and learning in the developing world. Science, 340(6130), 297-300.

Ladd, H. F. (2012). Education and poverty: Confronting the evidence. Journal of Policy Analysis and Management, 31(2), 203-227.

Lochner, L. (2011). Non-production benefits of education: Crime, health, and good citizenship (No. w16722). National Bureau of Economic Research.

Murnane, R. J., \& Ganimian, A. J. (2014). Improving educational outcomes in developing countries: Lessons from rigorous evaluations. Cambridge, MA: National Bureau of Economic Research.

Oreopoulos, P. (2003). Do dropouts drop out too soon? International evidence from changes in school-leaving laws (Working paper number 10155). National Bureau of Economic Research.

Reardon, S. F., Robinson, J. P., \& Waters, E. S. (2014). Patterns and trends in racial/ethnic and socioeconomic academic achievement gaps. In H. F. Ladd \& M. E. Goertz (Eds.), Handbook of research in education finance and policy (2nd ed., pp. 491-510). New York: Routledge.

Rouse, C. E. (2007). Consequences for the labor market. In C. Belfield \& H. M. Levin (Eds.), The price we pay: The economic and political consequences of inadequate education (pp. 99-124). Washington: Brookings Institution Press.

Sallis, E. (2014). Total quality management in education (3rd ed.). London: Kogan Page.

Wolfe, B. L., \& Haveman, R. H. (2002). Social and nonmarket benefits from education in an advanced economy. In Conference series-federal reserve bank of Boston (Vol. 47, pp. 97-131). Federal Reserve Bank of Boston, 1998.

Open Access This chapter is licensed under the terms of the Creative Commons Attribution 4.0 International License (http://creativecommons.org/licenses/by/4.0/), which permits use, sharing, adaptation, distribution and reproduction in any medium or format, as long as you give appropriate credit to the original author(s) and the source, provide a link to the Creative Commons licence and indicate if changes were made.

The images or other third party material in this chapter are included in the chapter's Creative Commons licence, unless indicated otherwise in a credit line to the material. If material is not included in the chapter's Creative Commons licence and your intended use is not permitted by statutory regulation or exceeds the permitted use, you will need to obtain permission directly from the copyright holder.

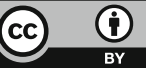

